\title{
CRECHE DE ONTEM E DE HOJE: O QUE OS PAIS ESPERAM DESSA INSTITUIÇÃ̃O? ${ }^{1}$
}

\author{
Maria Antonieta Nascimento Araújo Psicóloga, Mestre em Educação, professora \\ assistente (curso de Psicologia) e \\ coordenadora de projetos de extensão, Escola \\ Bahiana de Medicina e Saúde Pública. \\ Fernanda Souza Gama \\ Psicóloga, cursando a Pós Graduação em \\ Gestão Estratégica de Pessoas pelo Centro \\ Universitário Senac - SP. \\ Urbiana Silva Psicóloga, cursando a Pós Graduação em \\ Psicologia do Trânsito pelo Instituto Nacional \\ de Cursos - Incursos. Psicóloga do Centro de \\ Referência da Assistência Social - CRAS, \\ Tanque Novo - BA.
}

\begin{abstract}
Resumo
A importância histórica das creches teve origem no ingresso das mulheres no mercado de trabalho, a partir do advento da Revolução Industrial, ao permitir que aquelas que fossem mães participassem do processo produtivo. Nos seus primórdios, as creches ocupavam-se com os cuidados básicos para sobrevivência das crianças; atualmente essa concepção está ampliada, e favorece o desenvolvimento infantil nos seus diversos aspectos cognitivo, psicomotor, afetivo e psicossocial. Com isso elaboramos um estudo de caso exploratório, utilizando uma amostra de pais cujos filhos frequentam uma creche municipal da cidade de Salvador, com o objetivo de investigar o que eles esperam desta última para suas crianças, correlacionando essas expectativas com as propostas do governo para esse nível da educação infantil. Caracterizando o perfil familiar e mapeando os motivos que os levaram à escolha por creche para as crianças, analisamos a relação entre esses dois ambientes interseção que serve de contexto, na ótica estudada, ao desenvolvimento infantil. Como métodos para coleta de dados aplicamos questionários e realizamos a análise documental com estudo qualitativo e quantitativo dos resultados. Como aportes teóricos foram utilizados referenciais históricos do campo da educação sobre a origem e constituição de creches, além da abordagem sistêmica Bioecológica do campo da Psicologia do Desenvolvimento Humano, discutindo o binômio, creche-família. O estudo apontou que as expectativas dos pais em relação à creche alvo acompanharam a direção das propostas do governo para esse nível de educação infantil; ele também possibilitou o mapeamento de importantes aspectos da relação entre os dois ambientes.
\end{abstract}

Palavras-chave: Família; Educação infantil; Desenvolvimento humano; Psicologia da criança.

\section{CHILDCARE CENTERS FROM YESTERDAY AND TODAY: WHAT PARENTS EXPECT OF THIS INSTITUTION?}

\begin{abstract}
The historical importance of childcare centers originated with the entry of women to the labor market, since the Industrial Revolution, to allow those who were mothers, participate of the production process. In its early days, childcare centers used to do the basic care for child survival. Currently this concept expanded, and favors child development in many aspects - cognitive, psychomotor, affective and psychosocial. So we elaborated an exploratory case study with a sample of parents whose children are enrolled on a government childcare center of Salvador city in order to investigate what they expect from this institution to their kids, correlating this with the government's proposals for early childhood education. Characterizing the family profile and mapping their reasons to choice a childcare center for their children, we analyzed the relation between these two environments - intersection that serves as context in the perspective of this study, for child development. As methods for data collect we applied questionnaires and proceeded document analysis conducted with qualitative and quantitative study of their results. For this study we used as theoretical frameworks, the historical references from children education field and the origin and establishment of childcare centers, beyond the bioecological systemic

\footnotetext{
${ }^{1}$ Este projeto foi aprovado em Protocolo de no 101/2010, pelo Comitê de Ética em Pesquisa da Escola Bahiana de Medicina e Saúde Pública, sob o título "Um Estudo das Expectativas de Pais em Relação à Instituição
} Creche”. A mudança no título deve-se a uma maior adequação no conteúdo analisado.
\end{abstract}


approach - a psychology of human development field, discussing the binomial family - childcare center. The study founded that the parents expectations, considering the childcare center target, followed the government's proposals direction for this level of early childhood education. It also allowed the mapping of important aspects from the relationship between the two environments.

Keywords: Family; Early childhood education; Human development; Child psychology.

\section{Introdução}

As indagações de como as creches estão inseridas na dinâmica familiar e as expectativas que os pais de crianças aí matriculadas têm em relação a essa instituição serviram às inquietações que geraram esta investigação. Sabe-se que, entre os contextos do desenvolvimento infantil, o binômio creche-família tem importância singular e revelar aspectos do diálogo entre esses dois polos pode favorecer a compreensão dessa interseção, sobretudo quando os atores posicionam-se como sujeitos de pesquisa - dado relevante deste trabalho.

Assim, realizou-se um estudo de caso cujo objetivo foi investigar as expectativas de pais com relação a uma creche pública situada em Salvador-Bahia, confrontando tais expectativas com as formulações oficiais que expressam a concepção dessa instância educativa. $\mathrm{Na}$ interface dessas variáveis, buscou-se caracterizar o perfil familiar, além de mapear e analisar os motivos que levam pais à escolha por creches para as suas crianças.

O interesse por essa investigação encontra-se no fato de, cada vez mais, instituições infantis dessa natureza ocupar significativo espaço na sociedade. A sua origem tem lugar na Revolução Industrial, quando da inserção em grande escala da mulher no mercado de trabalho. A creche respondia, então, aos cuidados básicos para a sobrevivência das crianças, por permitir que as mães trabalhassem para ajudar no sustento da família.

$\mathrm{Na}$ atualidade, ampliou-se a concepção institucional de creche, ao se esperar que ela, além de atender aos cuidados básicos, também o faça em relação àqueles ligados a diversos aspectos do desenvolvimento infantil.

Com esse novo modelo e a crescente demanda de pais e responsáveis por tal instituição para seus filhos, a creche foi inserida nas políticas públicas do Ministério da Educação e a Lei das Diretrizes e Bases - $\operatorname{LDB}^{(1)}$ lhe garantiu lugar no sistema educacional, no nível da Educação Infantil.

Uma revisão bibliográfica possibilitou: contextualizar historicamente a creche, tomado-a como elemento da rede social de apoio à família, ${ }^{(2-3)}$ compreender o seu lugar na contemporaneidade como instituição educativa formal a partir de uma legislação vigente ${ }^{(1-4-5)}$ 
e discutir o binômio família-creche como contexto de desenvolvimento humano na perspectiva bioecológica. ${ }^{(6)}$

Com base nos dados coletados pela pesquisa percebemos que as famílias almejam a creche como uma das instituições responsáveis para a educação dos seus filhos e que essa favoreça o bom desenvolvimento infantil. Isso se opõe às expectativas, quando do surgimento dessa instituição, advindas de mães trabalhadoras fabris que buscavam apenas os cuidados básicos para os seus filhos na sua ausência.

A pesquisa revelou também que o trabalho continua sendo o principal motivo pela busca desse tipo de instituição infantil e isso aponta para mudanças culturais na configuração familiar. Nesse sentido, aqui serão apresentadas as concepções teóricas que tratam da contextualização histórica das creches, a perspectiva política que formaliza essa instituição na rede pública educacional e a sua interseção com a família, tendo em vista o desenvolvimento infantil. Ao final será apresentada a discussão dos resultados encontrados por esta investigação.

\section{A Creche como Rede Social de Apoio à Família}

As creches datam do início do século XX, surgidas em meio à crescente urbanização e à necessidade de utilização da força de trabalho feminina nas fábricas emergentes. A implantação de maquinário para ampliar a produção na era da Revolução Industrial permitiu que pessoas sem força muscular trabalhassem, incluídas as mulheres nesse grupo. ${ }^{(3)}$

É fato que essa entrada da mulher no mercado de trabalho significou grande conquista para o universo feminino, tendo em vista que muitas delas atingiram sua independência financeira, revertendo a condição de submissa aos proventos de seus esposos e companheiros. A conquista do trabalho remunerado foi "marco" que contribuiu para tirá-la do papel considerado inferior àqueles desempenhados pelos homens.

No entanto, paralelamente a essa conquista, as mulheres com filhos tiveram que aprender a lidar com a sua falta para esses, ainda pequenos, por um período de tempo considerável durante o dia, por suas jornadas de trabalho assim o exigirem. Tal fato provocou substancial alteração na forma de cuidar das crianças. Como os homens e as crianças maiores também trabalhavam nas indústrias têxteis que estavam surgindo, aquelas menores e recémnascidas ficavam em casa, sem alguém com responsabilidade que cuidasse delas. 
No cenário nacional, Mello ${ }^{(7)}$ cita que, na década de 20, com a chegada dos europeus em massa para o Brasil, quando esses passaram a ocupar a mão de obra nas indústrias, eram estas organizações de trabalho que dispensavam os cuidados aos filhos das operárias, ou seja, a creche era um benefício para os operários dessas indústrias, para amenizar os protestos femininos devidos às más condições de trabalho nessas fábricas. Nos anos subsequentes, até a década de 50, existiam poucas creches fora desses contextos trabalhistas, as quais eram de responsabilidade de entidades filantrópicas. Entre as décadas de 60 e 70, as mulheres de classe média começam a alcançar o mercado de trabalho e, em virtude disso, surgem as creches como agentes de promoção social.

Após a Revolução de 1964, uma iniciativa governamental criou a Fundação Nacional do Bem-Estar do Menor - FUNABEM, com creches destinadas às crianças carentes; essas eram de caráter assistencialista - como um favor oferecido à população. Nesse sentido, visavam à educação compensatória, tendo como base a teoria da privação cultural pela qual se buscava explicar a marginalização das camadas menos favorecidas. ${ }^{(7)}$

Ainda de acordo com a citada autora, na década de 70, a intensificação de reivindicações por creches, a partir de novos movimentos sociais, fez aumentar significativamente o número destas, organizadas e mantidas pelo poder público. Entretanto, muitas crianças continuaram sem assistência por esse serviço, fazendo com que surgissem medidas paliativas de caráter precário, como por exemplo, "os lares vicinais" ou as "creches domiciliares", ou seja, casa de famílias que atendiam, em média, a dez crianças durante o período em que as mães se ausentavam para trabalhar. ${ }^{(8)}$

Uma análise histórica levou Pacheco e Dupret ${ }^{(2)}$ a concluírem que a creche seria, portanto uma "herança" de movimentos operários e da preocupação médico-sanitarista da sociedade para com a população mais pobre. Além disso, pode-se afirmar que era marcadamente assistencial o trabalho desenvolvido por essas instituições, quando da sua origem, visando apenas suprir as necessidades da criança que não eram atendidas em seus ambientes domiciliares. Os cuidados não eram distintos daqueles oferecidos em asilos e internatos tais como alimentação, abrigo, segurança física e higiene, citam Veríssimo e Fonseca. ${ }^{(9)}$

Em vários países, e não só no Brasil, essas instituições objetivavam livrar as crianças pequenas da mortalidade; contudo, os cuidados institucionais eram de baixa qualidade, embora tivessem o intuito de isolar as crianças dos meios considerados perniciosos, tirando-as das ruas. Elas ofereciam educação de qualidade duvidosa, pois acreditavam que as crianças 
das quais cuidavam como "seres pobres" deveriam estar preparadas para o futuro a elas destinado. $^{(9)}$

Contrapondo-se a essa visão, nos dias atuais as creches são incentivadas a privilegiar, em seus projetos não somente os cuidados básicos infantis como também o desenvolvimento social; cognitivo; físico-motor; afetivo da criança. Além disso, elas ultrapassaram a esfera pública e hoje formam concomitantemente uma rede privada.

Assim, o processo educativo familiar passou a contar com a creche, uma vez que a criança passou a estar por longo período do dia nessa instituição. Isso determinou a associação família/creche.

Nos dias atuais, são evidentes as mudanças significativas que ocorreram na concepção de creche.

O reflexo disso é o fato de ela ter alcançado espaço importante na sociedade e passado a ser reconhecida pelo sistema educacional, etapa a se tratar na sessão seguinte deste artigo.

Desta forma, seja nos primórdios assistencialistas ou nas novas propostas educativas atuais, a creche sempre se configurou como uma rede social de importante apoio à família.

\section{A formalização da creche como educação infantil}

No Brasil, o ingresso da criança em uma creche está formalizado pelo Ministério da Educação como uma etapa que antecede ao seu ingresso na vida escolar. A partir da LDB Lei das Diretrizes e Bases da Educação, ${ }^{(1)}$ a creche passou a ser incluída como parte da educação infantil.

Desta maneira, para a implantação e desenvolvimento de uma creche é imprescindível uma proposta pedagógica bem fundamentada que direcione planejamento e sistemática capazes de atingir seus objetivos educacionais, como confirmam alguns autores. ${ }^{(10)}$

Podemos considerar que essa visão pedagógica e mais estruturada de uma creche é reflexo da inclusão dessa instituição no documento da Constituição Nacional, ${ }^{(11)}$ no capítulo que trata da Educação e naquele que consolida o Projeto de Lei de Diretrizes e Base da Educação, ${ }^{(1)}$ em que é contemplado o atendimento a crianças de 0 a 3 anos (em creches) e de 4 a 6 anos (em escolas).

$\mathrm{Na}$ Constituição, configura-se um plano nacional em longo prazo, com caráter legislativo, que confere estabilidade às iniciativas governamentais no âmbito educacional. Em consequência dos movimentos reivindicatórios por contextos coletivos para criança pequena, 
essa constituição estabeleceu que o atendimento às crianças de $0-6$ anos deveria ser direito destas, dever do Estado e opção da família.

Na Lei n ${ }^{\circ} 9.394,{ }^{(1)}$ são estabelecidas as Diretrizes e Bases da Educação Nacional LDB, e seus artigos $9^{\circ}$ e 87 impõem a criação, pela União, do Plano Nacional de Educação PNE - em parceria com os Estados e os municípios, instaurando assim a "Década da Educação".

Nessa perspectiva, a creche passa a ser reconhecida não somente como um local para a mãe deixar o filho enquanto trabalha, mas um centro de coparticipação com a família e a comunidade em favor do desenvolvimento integral e da educação da criança. Para se ter uma ideia da dimensão que esse serviço alcançou, levantamos que há cerca de 50 creches mantidas pela prefeitura no município de Salvador, sem se considerar as particulares ou as mantidas por instituições sem fins lucrativos.

Além disso, a regulamentação do Estatuto da Criança e do Adolescente - ECA ${ }^{(5)}$ também definiu lugar de prioridade nacional para a criança e o adolescente, vistos desde então como cidadãos - devendo ser respeitados como pessoas em desenvolvimento, com necessidades e características específicas. Aqui se insere também o cuidado com a educação, considerada importante fator de prevenção e promoção social.

Apesar desse importante lugar alcançado e das garantias da lei, a descontinuidade das políticas públicas no país não permite, muitas vezes, suprir essas instituições educacionais de recursos suficientes para o seu funcionamento. Assim, muitas delas têm infraestrutura e recursos humanos defasados. Por isso, existem creches públicas em que as crianças ainda não recebem os cuidados necessários, o que faz com que essas instituições voltem ao assistencialismo proposto pelas creches quando do seu início. ${ }^{(2)}$

Como se vê, a concepção mais recente de creche foi construída de forma gradativa, acompanhando a evolução nos determinantes históricos, políticos e sociais do contexto nacional, ao longo do tempo no qual a sociedade brasileira e suas instituições sofreram diversas mudanças. Um fator, no entanto, parece permanecer: a creche continua fazendo parte de uma rede social de apoio à família, agora com novas configurações. Esse binômio crechefamília, aspecto a ser tratado a seguir. 


\section{A Creche e a Família}

$\mathrm{O}$ art. n 29 da LDB diz: "a educação infantil, primeira etapa da educação básica, tem como finalidade o desenvolvimento integral da criança até seis anos de idade, em seus aspectos físico, psicológico, intelectual e social, complementando a ação da família e da comunidade". (1) Nessa lei, pontua-se a primeira caracterização da relação de vínculo entre creche e a família, além de ampliar seu papel para o compromisso com o desenvolvimento infantil.

Uma análise dessa citação leva ao destaque de duas instâncias - família e creche atreladas ao desenvolvimento da criança. Com relação à primeira, é fato que nos últimos tempos a família busca alternativas de cuidados para os seus filhos pequenos face à ocupação dos pais com o trabalho e a dificuldade de encontrar pessoas que executem esse serviço. Além disso, a emergência de novos arranjos familiares, o ingresso efetivo de mulheres, mães de família, no mercado de trabalho e a importância que se passou a dar às demandas dos cuidados infantis na ausência materna, levaram à valorização da alternativa por creche onde a criança passa boa parte de seu tempo.

Então, é possível afirmar, como mostra a literatura, ${ }^{(12)}$ que o advento da creche foi uma conquista para a mulher, por possibilitar a ela vivenciar experiências que vão além da maternidade como, por exemplo, poder estudar e trabalhar.

Antes de a mulher ingressar no mercado de trabalho da forma como ocorre atualmente e desfrutar de direitos garantidos e reconhecidos, o modelo predominante de família era o nuclear.

Neste modelo, os papéis de cada membro da família (pai, mãe e filho) eram bem definidos, deixando evidentes papéis femininos e masculinos, tendo o pai como o provedor financeiro e a mãe como responsável pelos cuidados referentes ao bem-estar e bom convívio dos integrantes da família. ${ }^{(13)}$

De acordo com Amorim, Vitória e Rossetti-Ferreira, ${ }^{(14)}$ família nuclear ainda é maioria na sociedade ocidental, no entanto, surgem novos padrões familiares, como por exemplo, presença de pais ou mães solteiras ou separadas, famílias com filhos de diferentes casamentos, famílias com filhos adotivos e famílias homoafetivas, dentre outras. A família acompanha as mudanças culturais ocorridas em toda sociedade e é possível ver diferentes tipos de arranjos familiares no contexto atual. ${ }^{(15)}$ 
Ainda com base em estudos desses autores, é enfatizado que, acompanhando esses novos modelos de famílias, novas configurações sociais também emergem, fazendo crescer a procura por creches, berçários e escolinhas infantis. Essas mudanças, ocorridas tanto na estrutura familiar quanto na significação das instituições infantis como creches, refletem-se nas relações entre os usuários dessas instituições e os profissionais destas, nas quais há expectativas de ambos os lados. ${ }^{(16)}$

Como resultado de todas as transformações socioeconômicas e ideológicas da sociedade brasileira, está se tornando unânime o fato de que o papel da creche não é apenas oferecer atendimento que garanta somente assistência e/ou custódia, mas o de ser instituição capaz de abarcar o trabalho educativo junto à criança e de compartilhá-lo com a família. Porém, em que pese esse delineamento de trabalho, Lordelo ${ }^{(17)}$ pontua existirem creches de cunho destacadamente educativo, diferenciando-se de outras que além de se preocuparem com a educação infantil direcionam também seu olhar para o desenvolvimento das diversas esferas da vida da criança - cognitiva, social, físico-motora, entre outras.

Essa preocupação com a primeira infância tem levado mães que não trabalham fora do ambiente doméstico a escolherem matricular seus filhos nas creches, desde cedo, como meio de socialização para eles, afirmam Rapopot e Piccinini. ${ }^{(18)}$ Esses autores consideram ainda que, além desse benefício, ao ingressar nessa instituição a criança tem a possibilidade de conviver com diferenças, tanto em relação com os adultos, quanto com os seus pares.

Apesar dessa valoração dada à creche pela família, o Plano Nacional de Educação PNE, como afirma Didonet, ${ }^{(19)}$ enfatiza que a educação infantil deve ser responsabilidade tanto da família quanto das instituições, incluindo as creches, e há a real necessidade das últimas de estarem cada vez mais presentes na sociedade, com o intuito de educar as crianças usuárias dos seus serviços em parceria com a família.

Desta forma, a "união" entre instituição educacional e a família pode promover, para ambas, aprendizagens mais amplas e de maior profundidade, uma vez que tais instâncias têm por objetivo buscar valores e expectativas, no que diz respeito ao processo de educação da criança. ${ }^{(19)}$ Isso reforçou a proposta aqui apresentada de buscar analisar tais expectativas em uma amostra de pais de uma creche pública. 


\section{Contribuições da Perspectiva Bioecológica do Desenvolvimento Humano}

Para a organização e funcionamento de uma creche, recomenda-se a parceria entre esta e a família, uma vez que ambas se tornam responsáveis pelo desenvolvimento infantil, mesmo que cada uma das partes tenha função diferenciada frente ao desenvolvimento da criança.

Partindo desse pressuposto, Bhering e De $\mathrm{Nez}^{(20)}$ enfatizaram a possibilidade de estas duas instituições desenvolverem, juntamente, situações complementares que visem à aprendizagem da criança, garantindo assim maior sucesso a esta. Além disso, os pais envolvidos com a creche/escola de seus filhos desenvolvem atitudes mais positivas ${ }^{(21)} \mathrm{em}$ relação a essa instituição, e também a si mesmos, tornando-se mais ativos em suas comunidades, além de construírem melhor relacionamento com os seus filhos.

Não apenas os pais se beneficiam com essa parceria pais-creche/escola, mas também a instituição de ensino, uma vez que, em decorrência dessa interação, os conflitos entre pais e instituições diminuem, fazendo com que se torne melhor o ambiente em que seus filhos se inserem. $^{(21)}$

Tais afirmações levam às considerações da Teoria Bioecológica do Desenvolvimento Humano de Bronfrenbrenner como referencial teórico para esse trabalho, por esta vertente da Psicologia procurar investigar o desenvolvimento a partir das interseções do indivíduo com os diversos sistemas ambientais dos quais participa e desses entre si. Bronfrebrenner ${ }^{(6)}$ acredita que o ambiente e o sujeito estão em constante interação, influenciando-se mutuamente.

Em uma perspectiva sistêmica, o tema pesquisado se configura de forma interdisciplinar, envolvendo fatores sociais, educacionais e do campo da psicologia imbricados numa rede de significações. Assim, a abordagem bioecológica apresenta meios favoráveis que possibilitam ao investigador analisar contextos complexos como este.

Bronfenbrenner, ${ }^{(6)}$ o primeiro investigador a sistematizar teoricamente a perspectiva bioecológica do desenvolvimento, descreve que o ambiente ecológico é organizado por um conjunto de sistemas interdependentes, e para efeito de pesquisa, devem ser categorizados como microssistema, mesossistema, exossitema e macrossistema.

O microssistema se refere aos ambientes imediatos do indivíduo, nos quais há relações interpessoais mais próximas, sendo a creche e a família, ambientes que proporcionam tal interação.

Em relação ao mesossistema, este é composto pela inter-relação de dois ou mais ambientes em que o indivíduo está inserido de forma ativa, ou seja, a relação estabelecida 
entre um conjunto de microssistemas do qual faz parte. Nesse âmbito, pesquisas relatam as influências mútuas na relação entre família e escola - incluindo-se aqui também a creche indicando que processos de continuidade e ruptura nessa relação provocam diferentes impactos na aprendizagem das crianças. ${ }^{(22)}$ Os autores mencionam ainda, que o envolvimento de famílias e creche ocasiona melhorias nos ambientes familiares. Tal envolvimento pode ter graus diferentes de intensidade, nível e tipo, a depender da cultura da escola/creche e da comunidade.

Esses achados refletem os estudos sobre mesossistema de Bronfebrenner ${ }^{(6)}$ que propõem existir uma rede de conhecimentos interambientes, constituídos por informações, experiências, percepções e expectativas que regem essa interação e influencia os sujeitos que deles participam.

O exossistema é definido como a relação entre um ou mais ambientes, nos quais não há a participação ativa do sujeito. Contudo, "os acontecimentos nesses ambientes afetam ou são afetados pelo ambiente em que se encontra a pessoa em desenvolvimento". ${ }^{(22)}$ Neste nível ambiental encontram-se as políticas públicas locais, nacionais e mesmo internacionais; e essas influenciam indiretamente o microssistema creche, a refletir, assim, de que forma serão executadas as atividades diárias dessa instituição e como serão estabelecidas as relações professor-aluno. $^{(23)}$

Por fim, o macrossistema, que se refere a padrões de valores e crenças de uma cultura ou subcultura implícitos no corpo de conhecimento, recursos materiais, costumes, estilo de vida, dentre outros. ${ }^{(6)} \mathrm{O}$ macrossistema permeia todos os outros sistemas ambientais.

A teoria bioecológica, com a sua natureza sistêmica, apoia o estudo científico do desenvolvimento do organismo humano, considerando-o ativo, na inter-relação com seu ambiente. Isso envolve um processo de mudança entre as suas características biológicas e psicossociais e mudanças do ambiente onde vive, criando estruturas dinâmicas que estão em intensa bidirecionalidade, ou seja, influenciam-se mutuamente.

Segue o percurso metodológico da investigação com a análise dos seus resultados.

\section{Percurso Metodológico e Resultados Encontrados}

A pesquisa proposta foi delineada como um estudo de caso de natureza exploratória, envolvendo levantamento bibliográfico ${ }^{(24)}$ e entrevistas com pessoas que tiveram experiência prática com o problema pesquisado. A escolha do contexto de investigação seguiu a sugestão 
de técnicos da Secretaria Municipal de Educação, que incentivaram a execução desse estudo de caso.

No levantamento prévio identificamos 110 crianças de 0-5 anos matriculadas na creche escolhida, quando então definimos, como critério para compor a amostra dos sujeitos, os pais ou responsáveis por crianças entre 0-2 anos, ou seja, 36 (trinta e seis) deles. Essa margem de idade foi definida em função dessas, na sua maioria, serem levadas pelos pais e não por terceiros para a creche, o que garantiria maior uniformidade da amostra. Foram tomados como informantes aqueles que levaram as crianças à creche no dia da aplicação do questionário.

Para obtenção de êxito nessa coleta de dados, optamos por uma aproximação inicial com os sujeitos em uma estratégia de sensibilização, realizando um contato prévio com a amostra de pais, quando esclarecemos o objetivo do estudo e eles foram convidados a responder ao questionário em outra data.

A creche pesquisada foi fundada em 29 de agosto de 1986, atendendo a crianças de 05 anos. Como recursos humanos possui trinta e seis profissionais entre professores, auxiliares de desenvolvimento infantil, cozinheira, uma lacterista (responsável pelo alimento dos bebês de 0-1 ano), equipe de higienização, auxiliares administrativos, lavadeira, merendeira, e equipe gestora. Essa é uma instituição registrada pela prefeitura de Salvador e recebe verba do Ministério de Educação e Cultura - MEC - para sua manutenção.

Ela reflete o percurso das políticas públicas, que na perspectiva bioecológica situa-se do exossistema, influenciando indiretamente o desenvolvimento infantil, a partir da consolidação do microssistema "creche" em interação com outro microssistema "família", estabelecendo um campo interativo entre ambos - mesossistema. A forma que as relações são estabelecidas e as ações são executadas neste âmbito são determinantes na estruturação do sujeito/criança, pois refletirão na sua subjetividade e no seu mundo simbólico.

Das 36 famílias identificadas de crianças de 0-2 anos, conseguiu-se compor uma amostra com os pais de 28 delas, ou seja, 77,7\% do universo pretendido. Os 22,2\% (08 pais) restantes não participaram da pesquisa por não compareceram e por não desejarem se submeter ao estudo.

Dos informantes, $17(60,7 \%)$ eram mães, $07(25 \%)$ pais e $3(10,7 \%)$ cuidadores e 1 $(3,6 \%)$ da amostra não se identificou quanto ao seu papel familiar. Diante desses dados observamos a participação significativa da presença masculina nos cuidados com as crianças pequenas nessa instituição, reforçando a ideia de Bustamante e Trad (25) de que todas as 
mudanças sociais têm repercussão também no que se refere à renegociação do significado da paternidade. Assim, na atualidade, além de os homens participarem ativamente da esfera econômica, da família, também estão presentes e dividem os cuidados da criança com a parceira, reforçando a multiplicidade de formas de se exercer a paternidade, ligada a diversos processos sociais e culturais. Na amostra, $25 \%$ dos pais demonstraram participar efetivamente da dinâmica do cuidado de levar os filhos para a creche, dividindo com as mães tal tarefa.

Em relação às idades paternas e maternas, entre os pais verificou-se que 11 (39,3\%) têm de 20-30 anos, $11(39,3 \%)$ de 30-40 anos, e $3(10,7 \%)$ de 40-50 anos e 3 (10,7\%) não responderam. Entre as mães, 12 (42,9\%) têm de 20-30 anos, 14 (50\%) de 30-40 e $2(7,1 \%)$ não responderam.

Observamos com esses dados, uma parcela significativa de pais entre a faixa etária de 30-40 anos que têm filhos de 0-2 anos. Entre eles, 64\% das mães trabalham, podendo-se inferir que se trata de uma escolha o fato de ter filhos com idade mais avançada. Relacionando isso às mudanças referentes aos papéis femininos, Soares e Carvalho (26) consideram tais mudanças correspondentes às transformações sociais e também ao surgimento do feminismo. A partir desse movimento e do desenvolvimento pelas ciências dos métodos contraceptivos, as mulheres passaram a ocupar novos papéis, saindo do ambiente doméstico (privado) para adentrar na esfera social (público). E isso reverberou na possibilidade de optarem por ter filhos mais tardiamente.

Confirmando essa concepção, Amorim, Vitória e Rossetti-Ferreira (14) ressaltaram que os cuidados direcionados à criança somente pela figura materna, vêm sendo contestados, pois esta tem a possibilidade de buscar cuidados alternativos como a creche, por exemplo.

Nos resultados obtidos, verificamos também que os níveis de educação formal dos sujeitos se diferenciam entre si: 01 participante $(3,6 \%)$ nunca estudou, $07(25 \%)$ tem primeiro grau incompleto, $01(3,6 \%)$ possui primeiro grau completo, $04(14,3)$ possuem segundo grau incompleto, $13(46,4 \%)$ concluíram o segundo grau, um respondeu que possui nível superior incompleto e $1(3,6 \%)$ deixou em branco essa questão.

Os dados referentes ao trabalho dos pais das crianças revelaram que 12 destes trabalham com carteira assinada (42,9\%), 12 (42,9\%) estão no trabalho informal, 1 (3,6\%) ocupa-se das atividades domésticas e $3(10,7 \%)$ não explicitaram sua ocupação. Quanto às mães pesquisadas, $9(32,1 \%)$ trabalham com carteira assinada, $9(32,1 \%)$ trabalham, porém não possuem registro na carteira de trabalho, 8 (29\%) destinam seu tempo às atividades domésticas e $2(7,1 \%)$ não responderam ao quesito. 
Retomando a análise a partir da perspectiva bioecológica de Bronfenbrenner, ${ }^{(6)}$ a mudança cultural marcada pelo ingresso da mulher no mercado de trabalho se constitui em outro ponto relevante do macrossistema, além do anteriormente já citado. Políticas públicas são organizadas com essas mudanças fortalecendo o lugar da creche como forte elemento na rede de apoio da família, configurando-a no exossistema de muitos contextos de desenvolvimento.

Dos 7 (25\%) pais que levam seus filhos à creche, $4(57,15 \%)$ trabalham no mercado informal e $3(42,85 \%)$ trabalham com carteira assinada. Presume-se que o fato de os pais trabalharem sem registro na carteira profissional possibilita horários mais flexíveis e maior disponibilidade para levar seus filhos à creche, oportunizando essa experiência de cuidado com o filho, fator importante para ambos.

Ainda sobre o perfil familiar, a pesquisa mapeou os arranjos familiares e encontrou 16 $(57,1 \%)$ sujeitos que mantêm união estável, mas não são casados, $6(21,4 \%)$ casados, 4 $(14,3 \%)$ separados, 1 (3,6\%) tem relação estável, mas mora em domicílio diferente e 1 (3,6\%) é viúva (o).

Por maior que seja a predominância da família nuclear na sociedade ocidental, Dessen e Braz (27) afirmam, que outras formas de padrões de institucionalizações de relações afetivas surgiram, havendo, assim, a pluralidade nos tipos de casamento e maneiras alternativas de família. Isso foi corroborado nos dados encontrados na pesquisa, tendo em vista que 57,1\% dos pais das crianças mantêm relação estável, entretanto, essa relação não está legalizada.

Em relação aos novos arranjos familiares 10 sujeitos (35,7\%) têm apenas um filho, 6 $(21,4 \%)$ têm dois filhos, $4(14,3 \%)$ têm três filhos, 3 (10,7\%) têm quatro filhos, e por último 3 $(10,7 \%)$ têm cinco filhos. Atualmente essa é a realidade, as famílias estão diminuindo o número de filhos. Estudos apontam que o retrato da família brasileira é marcado pela redução do número de filhos e esse fato pode estar relacionado com o controle da natalidade, como uma escolha da mulher, fruto de sua emancipação. ${ }^{(28)}$

Analisando os motivos que levaram os pais a matricularem seus filhos na instituição, $89,3 \%$, ou seja, 25 sujeitos, entre pais e mães, consideraram o trabalho como o principal deles.

Um aspecto que chamou a atenção na pesquisa foi o fato de mães, mesmo ocupandose de atividades domésticas, optarem por colocar seus filhos na creche. Isso corrobora a revisão teórica de Rapopot e Piccinini ${ }^{(18)}$ ao afirmarem existir um segmento de mães que, mesmo não trabalhando fora do ambiente doméstico, buscam os serviços da creche como 
meio de socialização para seus filhos. Essa concepção é também comungada por Bahia, ${ }^{(29)}$ que encontrou esse mesmo resultado em suas pesquisas.

Além do trabalho e da socialização, outros motivos foram levantados como causas para matrícula em creches; fatores como educação e desenvolvimento também foram ressaltados, nas porcentagens $1(3,6 \%)$ e $2(7,1 \%)$, respectivamente. Esses dados refletem as transformações que ocorreram na organização familiar e nos papel social desempenhado pela creche ao longo das décadas.

Como mencionado nesta pesquisa, o trabalho foi um dos motivos mais ressaltados pelos pais em relação à matrícula das crianças na creche. Afirmamos então, que, no século XXI, isso continua a ser o principal motivo para o seu advento, ou seja, ela surgiu como alternativa de cuidado para mães que saíam para trabalhar. A grande diferença era a creche ser um local cuja função era apenas suprir as necessidades básicas da criança, preocupando-se com sua sobrevivência. Essa concepção mudou e está fundamentada pelas propostas de políticas públicas que a inseriram no sistema da rede educacional.

Assim, quando os sujeitos do estudo fazem referência à educação como principal expectativa, isso leva à análise de que a sua concepção relativa à creche se assemelha àquela pretendida pelas políticas públicas, conforme atestam os documentos legais, os quais postulam que essa instituição deve ter função educativa. Bahia ${ }^{(29)}$ afirma que nessa função educativa, o cuidar e o educar estão intimamente interligados e rompe com a concepção do cuidar voltado apenas para o assistencialismo e o educar direcionado à visão escolar, pois a educação infantil diverge do ensino fundamental.

Em relação às expectativas dos pais, identificamos que a maioria deles procura essa instituição com o intuito de proporcionar educação para seus filhos. A palavra educação apareceu nas respostas dos sujeitos com bastante frequência, de forma muito significativa, ou seja, em $75 \%$ delas. Fazendo-se um cruzamento entre as expectativas dos participantes em relação ao papel da creche e o seu grau de escolaridade, é evidente que a diversidade nos níveis de escolaridade dos pais não diferencia as suas expectativas com relação à creche para seus filhos, visto que as respostas foram coincidentes na sua maioria e a educação o fator preponderante nas afirmativas.

Desta forma, para ratificar esses dados, torna-se unânime, no campo teórico, o fato de não ser suficiente o atendimento que garanta apenas assistência e/ou custódia à criança em uma creche, mas uma instituição que seja capaz de abarcar trabalho educativo junto a elas e de compartilhá-lo com a família. ${ }^{(10)}$ 
Sabendo-se que o art. 29 da LDB visa ao desenvolvimento integral da criança nos seus aspectos físicos, psicológicos e sociais, conjuntamente com a família e a comunidade na qual está inserida, é possível afirmar que a creche, alvo desta pesquisa, está respaldada nessa prerrogativa. Segundo a diretora da instituição, além de viabilizar os cuidados com a higiene e alimentação das crianças, a instituição procura realizar, em parceria com familiares, um trabalho direcionado ao desenvolvimento integral do ser humano. Assim, acredita que para o bom funcionamento da estrutura física, psíquica e social da criança, o cuidar e o educar sejam indissociáveis.

\section{Considerações Finais}

Sabendo das modificações ocorridas na sociedade, acreditamos que foi de extrema relevância a perspectiva histórica resgatada nesse estudo a respeito das creches no Brasil e a abordagem aos seus parâmetros legais e aos princípios que regem a educação infantil, pois atualmente essa instituição está consolidada em projetos de leis importantes para o contexto do sistema educacional, diferenciando-se de contextos assistencialistas anteriores.

Diante dessas mudanças, no que diz respeito à concepção de creche e também das transformações ocorridas na esfera familiar, verificamos que é imprescindível parceria entre os microssistemas creche-família, visto que a interseção entre os dois ambientes possibilita meios satisfatórios para o processo de educação e desenvolvimento da criança.

Os dados coletados no campo empírico apontam para o alcance dos objetivos propostos, ao verificar que as expectativas de pais pesquisados corroboram o que está previsto nos projetos de leis acerca da instituição creche, uma vez que eles esperam que a creche proporcione educação para seus filhos. Além disso, a maior parcela dos participantes tem o trabalho como motivo principal para a matrícula das crianças na instituição pesquisada e este motivo se assemelha àquele que contribuiu para o surgimento da creche. A diferença está nas expectativas.

A confirmação da pesquisa reforça o seu compromisso psicossocial, uma vez que abarca questões referentes a creches que se apresentam como recurso social com possibilidade de repercussões não somente na criança como também nas famílias.

O trabalho não tem a pretensão de exaurir a discussão acerca da temática, uma vez que essa abordagem é bastante vasta e requer a construção de mais pesquisas referentes ao tema. Ademais, a escassez de literatura que aborde o tema investigado reforça a importância desta 
pesquisa para o campo da psicologia, sobretudo com a utilização de referenciais teóricos sistêmicos, como a teoria bioecológica que auxilia ao recorte dos contextos, para fins investigativos.

Finalmente, acreditamos que a construção do presente estudo pôde criar alternativas de sensibilização para a aproximação da creche alvo dessa pesquisa com as famílias das crianças nela matriculadas, destacando com isso a importância social da ciência.

\section{Referências}

1 Brasil. Ministério da Educação. Lei no 9.394/96, de 20 de dezembro de 1996. Estabelece as diretrizes e bases da educação nacional [Internet]. Brasília; 1996 [acesso em 2012 Out 20]. Disponível em: http://www.planalto.gov.br.

2 Pacheco ALPB, Drupet L. Creche: Desenvolvimento ou Sobrevivência? Psicol. USP, São Paulo. [Internet] 2004; 15(3):103-116. [acesso em 2008 Out 2]. Disponível em: http://www.scielo.br/pdf/pusp/v15n3/24607.pdf.

3 Vicenzi APM, Treichel A. Ascensão da Mulher no Mercado de Trabalho. Revista de Divulgação Técnico-Científica do ICPG [Internet]. 2007 Jul/Dez;3(11) [acesso em 2008 Maio 8]. Disponível em: http:// www.icpg.com.br.

4 Brasil. Lei no 10.172/01, de 09 de janeiro de 2001. Aprova o Plano Nacional de Educação e dá outras providências [Internet]. Brasília; 2001[acesso em 2012 Out 20]. Disponível em: http://www.planalto.gov.br.

5 Brasil. Lei no 8.069, de 13 de julho de 1990. Dispõe sobre o Estatuto da Criança e do Adolescente e dá outras providências [Internet]. Brasília; 1990 [acesso em 2012 Out 20]. Disponível em: http://www.planalto.gov.br.

6 Bronfenbrenner U. A ecologia do desenvolvimento humano: experiências naturais e planejadas. Porto Alegre: Artes Médicas; 1996.

7 Mello DT. Educação e Cuidado em Creches: Pós-LDB 9394/96: o Projeto Fundo do Milênio para a Primeira Infância. In: V Mostra de Atividades Extensionistas e projetos Sociais, Guaíba, 2007. Anais do X Seminário Intermunicipal de Pesquisa e Iniciação Científica da Ulbra/Guaíba [Internet]; 2007. 1. [acesso em 2010 Maio 2]. Disponível em: http://guaiba.ulbra.tche.br/pesquisas/2008/artigos/pedagogia/382.pdf.

8 Dias IS. A relação educadora-bebê laços possíveis. [mestrado]. Faculdade de Educação [Internet]. Universidade Federal do Rio Grande do Sul - UFRS. Porto Alegre; 2010. $91 \mathrm{f}$. [acesso em 2010 Out 3]. Disponível em:

http://www.lume.ufrgs.br/bitstream/handle/10183/24819/000749284.pdf? sequence=1. 
9 Veríssimo MDLOR, Fonseca RMGS. O cuidado da criança segundo trabalhadoras de creches. Rev. Latino-Am. Enfermagem, Ribeirão Preto [Internet]. 2003 fev;(11)1:28-35. [acesso em 2010 Abr 12]. Disponível em:

http://www.oei.es/inicial/articulos/cuidado_crianca.pdf.

10 Vitória T, Rossetti-Ferreira MC. Processos de adaptação na creche. Cadernos de Pesquisa. [Internet]. 1993; 86:55-64. [acesso em abr 2010 Abr 12]. Disponível em:

http://www.scielo.br.

11 Brasil. Constituição da República Federativa do Brasil [Internet]. Brasília: Senado Federal, 1988[acesso em 2012 Out 2012]. Disponível em: http://www.planalto.gov.br.

12 Godoi EG. Avaliação na creche: O caso dos espaços educativos não escolares [tese].

Faculdade de Educação [Internet]. Universidade Estadual de Campinas - UNICAMP; 2006. 224 f. [acesso em 2010 Maio 15]. Disponível em: http://cutter.unicamp.br/document/?code=vtls000401477.

13 Meira MCR. Relação Creche e Família: Mito ou Realidade. 2004 [dissertação]. Programa de Pós-graduação em Enfermagem. Universidade Federal do Paraná - UFPR [Internet]. Curitiba; 2004. 118 f. [acesso em 2010 Maio 15]. Disponível em: http://dspace.c3sl.ufpr.br.

14 Amorim KS, Vitória T; Rossetti-Ferreira MC. Rede de significações: perspectiva parágrafo análise da inserção de bebês na creche. Cadernos de Pesquisa. São Paulo. [Internet]. 2000 Mar; (109):115-144. [acesso 2008 Maio 8]. Disponível em:

http://www.scielo.br/pdf/cp/n109/n109a06.pdf.

15 Staudt ACP, Wagner A. Paternidade em tempos de mudança. Psicol. teor. prat. [Internet]. 2008 Jun; 10(1):174-185. [acesso em 2010 Abr 24]. Disponível em:

http://pepsic.bvsalud.org/pdf/ptp/v10n1/v10n1a13.pdf.

16 Maranhão DG, Sarti CA. Creche e família: uma parceria necessária. Cad. Pesquisa, São Paulo. [Internet]. 2008 Jan/Abr; 38(133):171-194. [acesso em 2010 Ago 20]. Disponível em: http://www.scielo.br/pdf/cp/v38n133/a08v38n133.pdf.

17 Lordelo ER. Agora vá com a tia que a mamãe vem mais tarde: creche como contexto brasileiro de desenvolvimento. In: Lordelo ER, Carvalho AMA, Koller SH, organizadores. Infância brasileira e contextos de desenvolvimento. São Paulo/Salvador: Casa do Psicólogo/EDUFBA; 2002. p. 77-97.

18 Rapopot A, Piccinini C. O ingresso e adaptação de bebês e crianças pequenas à creche: alguns aspectos críticos. Psicologia Reflexão e Crítica, Porto Alegre. [Internet]. 2001; 14(1):81-95. [acesso em 2008 Out 2]. Disponível em: http://www.scielo.br/pdf/prc/v14n1/5209.pdf.

19 Didonet V. Creche: a que veio... Para onde vai. Em Aberto. Brasília. [Internet]. 2001 Jul; 18(73):11-27. [acesso em 2010 Jan 10]. Disponível em:

http://www.rbep.inep.gov.br/index.php/emaberto/article/viewFile/1107/1007. 
20 Bhering E, De Nez TB. Envolvimento de pais em creche: possibilidades e dificuldades de parceria. Psicologia: Teoria e Pesquisa, Brasília. [Internet]. 2002 Abr; 18(1):63-73. [acesso em 2010 Abr 24]. Disponível em:

http://www.scielo.br/pdf/ptp/v18n1/a08v18n1.pdf.

21 Cavalcante R. Os pais da escola de colaboração: envolvimento educacional. Psicol. esc. educ. [Internet]. 1998; 2(2):153-160. [acesso em 2010 Maio 2]. Disponível em: http://pepsic.bvs-psi.org.br/scielo.

22. Polonia AC, Dessen MA, Silva NLP. O modelo bioecólogico de Bronfenbrenner: contribuições para o desenvolvimento humano. In: Dessen MA, Costa Júnior AL. A ciência do desenvolvimento humano: tendências atuais e perspectivas futuras. Porto Alegre: Artmed; 2005, p. 71-89.

23 Polonia AC, Senna SRCM. A ciência do desenvolvimento humano e suas interfaces com a educação. In: Dessen MA, Costa Júnior AL. A ciência do desenvolvimento humano: tendências atuais e perspectivas futuras. Porto Alegre: Artmed; 2005, p. 190-209.

24 Gil AC. Como Elaborar Projetos de Pesquisa. 4로 ed. São Paulo: Atlas, 2002.

25. Bustamante V, Trad LAB. Participação paterna no cuidado de crianças pequenas: um estudo etnográfico com famílias de camadas populares. Cad. Saúde Pública, Rio de Janeiro. [Internet]. 2005 Nov/Dez; 21(6):1865-1874. [acesso em 2010 Maio 2]. Disponível em: http://www.scielo.br/pdf/csp/v21n6/26.pdf. 